\title{
Determinants of Market Share of For-Profit Hospitals: An Empirical Examination
}

\author{
Seungchul Lee ${ }^{1}$, Chune Young Chung ${ }^{2, *}$, Hong Kee Sul ${ }^{3}$ and Yunjae Lee ${ }^{4}$ \\ 1 Samsung Economic Research Institute, Seoul 137-955, Korea; lsc1026@gmail.com \\ 2 School of Business Administration, College of Business and Economics, Chung-Ang University, \\ Seoul 156-756, Korea \\ 3 Wharton Research Data Service, The Wharton School, University of Pennsylvania, Philadelphia, PA 19104, \\ USA; hongkee@wharton.upenn.edu \\ 4 Graduate School of Business Administration, Chung-Ang University, Seoul 156-756, Korea; \\ dldbswo35@naver.com \\ * Correspondence: bizfinance@cau.ac.kr
}

Received: 11 August 2017; Accepted: 28 September 2017; Published: 3 October 2017

\begin{abstract}
This study estimates the effects of a prospective payment system on the growth of for-profit hospitals. The empirical results show that the proportion of patient care paid for by Medicare managed care has a positive, statistically significant relationship with the market share of for-profit hospitals. Medicare managed care reimburses health care providers prospectively, and a larger portion of prospective reimbursements is received by for-profit hospitals, whose market share consequently increases. In addition, the proportion of patients with Medi-Cal and third party managed care has a positive, statistically significant relationship with the market share of for-profit hospitals.
\end{abstract}

Keywords: hospital reimbursement; for-profit hospital; market share; prospective reimbursement; nonprofit hospital

\section{Introduction}

The significant growth of for-profit hospitals is the most important change in the predominantly nonprofit hospital market in the last two decades. ${ }^{1}$ The growth in the market share of for-profit hospitals among U.S. community hospitals in the last two decades is an example of this trend (from 1980 to 2007, for-profit hospital growth was 5.3\%, which is comparatively faster than the $2.7 \%$ growth of nonprofit hospitals and the $-7.8 \%$ growth of government hospitals (Lee and Rosenman 2013).

There are two traditional views on why this change has occurred. First, for-profit hospitals are organized and operated by physicians who are unable to obtain admitting privileges at existing nonprofit hospitals. This distinction plays an important role in providing a financial advantage to for-profit hospitals, since for-profit hospitals are able to make a direct profit from the patients in their hospitals. Araújo et al. (2014) document the determinants of efficiency for Brazilian for-profit hospitals, and Langland-Orban et al. (2015) explain the differences in operating profitability between for-profit and nonprofit hospitals by analyzing Florida community hospitals during Medicare policy changes from 2000 to 2010. However, Woolhandler and Himmelstein (2004), Gawande (2009), and Teno et al. (2010) document that for-profit hospitals tend to provide unnecessary care and bill Medicare more while thy do not necessarily yield substantial enhancements in health outcomes.

1 The literature extensively documents the competition between for-profit and nonprofit hospitals. See Friesner and Rosenman (2002), Solutions (2004), Lakdawalla and Philipson (2006), Brekke et al. (2011), Herr (2011), and Gaynor and Town (2012), among others, for details. 
The second explanation for the growth of for-profit hospitals is that hospitals organized for profit can respond much more rapidly to an increase in patients' demands than nonprofit hospitals can. This difference can be explained by the financial sources of nonprofit hospitals. Nonprofit hospitals have relied heavily on capital contributions through either private charity or government aid. This financial capital structure can be an obstacle for nonprofit hospitals in responding to market change. For example, in some areas, rapid population growth generated a higher demand for additional hospital beds that was not immediately fulfilled by nonprofit hospitals, perhaps because the personal incomes of the people in these areas were not initially high enough to provide the necessary charitable support. Therefore, periods of rapid population growth have allowed for-profit hospitals to enter the industry (Bays 1983). In addition, Sloan (2000) document that the prices for health care services in for-profit nonprofit hospitals are as high as the ones in for-profit hospitals.

However, one question that has arisen from the above explanations is why there are no concerns about hospital financing or the reimbursement system. It is essential to investigate the hospital market structure since reimbursement schemes affect hospitals' profits differently depending on the type of ownership. Reimbursement especially affects hospital behavior because it facilitates the acquisition of medical technologies, which have a crucial role in attracting patients. Chang and Jacobson (2011) argue that for-profit hospitals provide different quantities of health care and thus this incurs heterogeneity in the Medicare reimbursements compared to nonprofit counterparts.

The objective of this study is to estimate the effects of a prospective payment system on the growth of for-profit hospitals. Our central hypothesis is that the prospective payment system helps for-profit hospitals capture a larger market share, and this study is primarily concerned with addressing this claim.

\section{Empirical Approach}

To investigate how prospective reimbursement helps to increase the market share of for-profit hospitals, this study models the market share of each for-profit hospital in each time period separately as applying the theoretical implications in Lee (2010) and Lee and Rosenman (2013). The basic regression model is of the form:

$$
s_{i t}=\alpha^{\prime} p_{i t}+\beta^{\prime} t_{i t}+\gamma^{\prime} d_{i t}+e_{i t}
$$

where, for the $i$ th for-profit hospital in time period $t, s_{i t}$ is the hospital's market share, $p_{i t}$ represents the proportion of the hospital's inpatients covered by different payer types, $t_{i t}$ is the type of care provided to patients, and $d_{i t}$ is the hospital's direct expenses. $\alpha^{\prime}, \beta^{\prime}$, and $\gamma^{\prime}$ are vectors of the parameters to be estimated and potentially take on different values in each time period, and $e_{i t}$ is an error term that may include both individual-specific and idiosyncratic elements.

The dependent variable, the market share of for-profit hospitals, is calculated as the number of discharges from the selected for-profit hospitals divided by the total number of discharges from all of the hospitals in the market in each year. There are three categories of independent variables: the proportion of inpatient services utilization by payer type, the number of licensed beds by type of care, and direct expenses by cost center group.

The payer types include Medicare, Medicaid, "other third party," indigent programs, and self-pay. Furthermore, each of the above payer types (Medicare, Medicaid, other third parties, indigent programs, and self-pay) is further specified as "managed" or "traditional" care. This study only considers patients covered by a Medicare or Medicaid managed care plan, since they represent the majority of patients covered by prospective reimbursement.

Utilization according to the type of care provided by each hospital is also included as an independent variable to discern the types of care hospitals focus on to attract more patients. The types of care provided by each hospital are defined as acute, psychiatric, chemical dependency, rehabilitation, and long-term care. 
The last independent variable category is direct expenses. This variable is included in Equation (1) to assess how hospitals' expenditures affect the market share of for-profit hospitals. Direct expenses are categorized as ambulatory, ancillary, purchased, and general services and as hospital and malpractice insurance.

Since the market share of for-profit hospitals has a longitudinal character, testing for random effects is required. First, the Breusch and Pagan Lagrange multiplier test is conducted. Then, to test for the orthogonality of the random effects and regressors, the Hausman test is also conducted.

\section{Sample}

\subsection{Data and Variables}

The data comes from the Office of Statewide Health Planning and Development (OSHPD), which provides annual financial data for licensed hospitals in California (see Brown et al. (2011) for details). All hospitals in the state provide inpatient and outpatient medical services in the areas of general, pediatric, psychiatric, and specialty care. The ownership type varies and can be categorized as nonprofit, for-profit, state, government, or district. This study uses data from 85 general for-profit hospitals for the sample period from 2003 to 2007.

Hospital accounting and financing reporting began in California with the passage of the California Hospital Disclosure Act by the California Legislature, Senate Bill 283, in 1971. The Act created the California Hospital Commission and gave it the authority to set standards for uniform hospital accounting and reporting to enable the public, third-party payers, and other interested parties to analyze the financial aspects of hospitals in California. These reports include general hospital information, services utilization data, patient revenues, expenses, balance sheets, and labor and productivity data, and they also provide extensive information about patient origin and the market shares of the selected hospitals.

Table 1 presents the number and percentage of California general hospitals by ownership type (for-profit and nonprofit), size, and year (2003 through 2007). The number of hospitals changes minimally during the study period. ${ }^{2}$ Nonprofit hospitals are the dominant ownership type in California, which is consistent with the trends in the U.S. hospital market. The average numbers of licensed beds of for-profit and nonprofit hospitals are 170 and 265, respectively, which implies nonprofit hospitals also dominate in size in California.

Table 1. Number and Percentage of California General Hospitals by Ownership Type.

\begin{tabular}{cccccccccccc}
\hline $\begin{array}{c}\text { Hospital Size (Number } \\
\text { of Licensed Beds) }\end{array}$ & \multicolumn{2}{c}{2003} & \multicolumn{2}{c}{ 2004 } & \multicolumn{2}{c}{2005} & \multicolumn{2}{c}{2006} & \multicolumn{2}{c}{$\mathbf{2 0 0 7}$} \\
\cline { 2 - 11 } & FPH & NPH & FPH & NPH & FPH & NPH & FPH & NPH & FPH & NPH \\
\hline$<50$ & 5 & 15 & 4 & 16 & 3 & 16 & 3 & 16 & 4 & 16 \\
$50-100$ & 13 & 18 & 13 & 18 & 15 & 16 & 16 & 16 & 14 & 15 \\
$100-150$ & 23 & 23 & 23 & 20 & 23 & 22 & 24 & 23 & 24 & 24 \\
$150-200$ & 21 & 25 & 21 & 24 & 20 & 23 & 20 & 23 & 20 & 21 \\
$200-250$ & 11 & 20 & 11 & 16 & 12 & 17 & 11 & 16 & 12 & 18 \\
$250-300$ & 3 & 16 & 3 & 22 & 3 & 19 & 3 & 21 & 2 & 20 \\
$300-350$ & 1 & 18 & 1 & 16 & 1 & 15 & 1 & 17 & 1 & 17 \\
$350-400$ & 4 & 13 & 4 & 16 & 3 & 17 & 3 & 15 & 2 & 13 \\
$400-450$ & 3 & 14 & 3 & 12 & 4 & 13 & 4 & 12 & 5 & 15 \\
\hline
\end{tabular}

2 In previous years, the ownership types of some hospitals changed from for-profit to nonprofit and vice versa. Spetz et al. (1999) highlight little change in the overall share of hospitals held by nonprofit and for-profit owners from 1986-1999. Of the 296 ownership changes between 1986 and 1996, only 13 involved conversions from nonprofit to for-profit ownership. During the same period, 12 hospitals switched from for-profit to nonprofit ownership. About 80 percent of hospital ownership changes in California did not involve any change in the nonprofit or for-profit status of the hospital (Spetz et al. 1999). 
Table 1. Cont.

\begin{tabular}{ccccccccccc}
\hline $\begin{array}{c}\text { Hospital Size (Number } \\
\text { of Licensed Beds) }\end{array}$ & \multicolumn{2}{c}{$\mathbf{2 0 0 3}$} & \multicolumn{2}{c}{$\mathbf{2 0 0 4}$} & \multicolumn{2}{c}{$\mathbf{2 0 0 5}$} & \multicolumn{2}{c}{$\mathbf{2 0 0 6}$} & \multicolumn{2}{c}{$\mathbf{2 0 0 7}$} \\
\cline { 2 - 11 } & FPH & NPH & FPH & NPH & FPH & NPH & FPH & NPH & FPH & NPH \\
\hline $450-500$ & 0 & 5 & 0 & 7 & 0 & 8 & 0 & 8 & 0 & 9 \\
$500-550$ & 0 & 9 & 0 & 8 & 0 & 6 & 0 & 7 & 0 & 6 \\
$550-600$ & 0 & 2 & 0 & 2 & 0 & 4 & 0 & 4 & 0 & 3 \\
$600-650$ & 0 & 0 & 0 & 1 & 0 & 1 & 0 & 1 & 0 & 3 \\
$650-1000$ & 0 & 4 & 0 & 4 & 0 & 4 & 0 & 4 & 0 & 3 \\
$>1000$ & 1 & 2 & 1 & 2 & 1 & 3 & 1 & 1 & 1 & 1 \\
Total & 85 & 184 & 84 & 184 & 85 & 184 & 85 & 184 & 85 & 184 \\
Percentage & 31.5 & 68.5 & 31.5 & 68.5 & 31.5 & 68.5 & 31.5 & 68.5 & 31.5 & 68.5 \\
Average Number of & 168 & 257 & 167 & 260 & 167 & 269 & 165 & 264 & 180 & 264 \\
Licensed Beds & & & & & & & & & \\
\hline
\end{tabular}

Notes: The total number of general hospitals in California in the sample is 269. FPH and NPH denote for-profit hospitals and nonprofit hospitals, respectively.

\subsection{Market Share}

Before describing the data further, let us discuss the overall trends for California hospitals. Nonprofit hospitals dominate in terms of both average and cumulative market share in California. The average market share is calculated as the number of discharges from the selected hospitals divided by the total number of discharges from all of the hospitals in the market in each year. The cumulative market share of each hospital type is calculated as the sum of the market share of each hospital of that type in each year.

Tables 2 and 3 show the average and cumulative market shares, respectively, of hospitals by ownership type. Table 2 shows that the growth of for-profit hospitals is also reflected in their average market share. The average market share of for-profit hospitals in California grows from $0.197 \%$ to $0.208 \%$. The average market share of for-profit hospitals with under 100 licensed beds slightly decreases, whereas that of hospitals with over 100 licensed beds increases. Interestingly, the average market share of nonprofit hospitals is slightly decreasing, and this pattern is especially evident among nonprofit hospitals that have between 200 and 250 licensed beds. Table 3 shows that the cumulative market share of for-profit hospitals grows slightly during the study period, whereas nonprofit hospitals do not exhibit consistent trends. However, at the market level in California, the cumulative market share of nonprofit hospitals is around $60 \%$, whereas for for-profit hospitals, it is around $15 \%$.

Table 2. Average Market Share (Percentage) of California General Hospitals with Licensed Beds by Ownership Type.

\begin{tabular}{ccccccccccc}
\hline $\begin{array}{c}\text { Hospital Size } \\
\text { (Number of } \\
\text { Licensed Beds) }\end{array}$ & \multicolumn{2}{c}{ 2003 } & \multicolumn{2}{c}{ 2004 } & \multicolumn{2}{c}{ 2005 } & \multicolumn{2}{c}{ 2006 } & \multicolumn{2}{c}{ 2007 } \\
\cline { 2 - 11 }$y$ & FPH & NPH & FPH & NPH & FPH & NPH & FPH & NPH & FPH & NPH \\
\hline$<50$ & 0.038 & 0.051 & 0.037 & 0.048 & 0.036 & 0.051 & 0.026 & 0.051 & 0.018 & 0.050 \\
$50-100$ & 0.077 & 0.109 & 0.071 & 0.101 & 0.074 & 0.105 & 0.067 & 0.104 & 0.066 & 0.106 \\
$100-150$ & 0.148 & 0.183 & 0.148 & 0.193 & 0.157 & 0.181 & 0.151 & 0.178 & 0.151 & 0.181 \\
$150-200$ & 0.218 & 0.298 & 0.213 & 0.298 & 0.219 & 0.290 & 0.229 & 0.299 & 0.291 & 0.292 \\
$200-250$ & 0.237 & 0.400 & 0.229 & 0.362 & 0.234 & 0.352 & 0.239 & 0.349 & 0.270 & 0.340 \\
$250-300$ & 0.423 & 0.431 & 0.397 & 0.443 & 0.355 & 0.438 & 0.369 & 0.442 & 0.410 & 0.463 \\
$300-350$ & 0.371 & 0.481 & 0.289 & 0.485 & 0.278 & 0.471 & 0.266 & 0.477 & 0.269 & 0.456 \\
$350-400$ & 0.616 & 0.570 & 0.618 & 0.554 & 0.616 & 0.557 & 0.597 & 0.561 & 0.610 & 0.550 \\
$400-450$ & 0.384 & 0.569 & 0.478 & 0.551 & 0.472 & 0.536 & 0.483 & 0.535 & 0.426 & 0.525 \\
$450-500$ & 0 & 0.568 & 0 & 0.688 & 0 & 0.636 & 0 & 0.634 & 0.608 & 0.681 \\
$500-550$ & 0 & 0.847 & 0 & 0.746 & 0 & 0.739 & 0 & 0.710 & 0 & 0.726 \\
\hline
\end{tabular}


Table 2. Cont.

\begin{tabular}{ccccccccccc}
\hline $\begin{array}{c}\text { Hospital Size } \\
\text { (Number of } \\
\text { Licensed Beds) }\end{array}$ & \multicolumn{2}{c}{$\mathbf{2 0 0 3}$} & \multicolumn{2}{c}{ 2004 } & \multicolumn{2}{c}{2005} & \multicolumn{2}{c}{2006} & \multicolumn{2}{c}{$\mathbf{2 0 0 7}$} \\
\cline { 2 - 11 } & FPH & NPH & FPH & NPH & FPH & NPH & FPH & NPH & FPH & NPH \\
\hline $550-600$ & 0 & 0.589 & 0 & 0.588 & 0 & 0.702 & 0 & 0.670 & 0 & 0.603 \\
$600-650$ & 0 & 0 & 0 & 0.719 & 0 & 0.717 & 0 & 0.737 & 0 & 0.911 \\
$650-1000$ & 0 & 1.118 & 0 & 0.102 & 0 & 1.133 & 0 & 1.123 & 0 & 1.139 \\
$>1000$ & 0.202 & 1.027 & 0 & 1.036 & 0 & 0.948 & 0 & 0.953 & 0 & 0.924 \\
Total & 0.197 & 0.386 & 0.202 & 0.384 & 0.203 & 0.384 & 0.202 & 0.382 & 0.208 & 0.382 \\
\hline
\end{tabular}

Notes: The total number of general hospitals in California in the sample is 269. FPH and NPH denote for-profit hospitals and nonprofit hospitals, respectively.

Table 3. Cumulative Market Share (Percentage) of California General Hospitals by Ownership Type.

\begin{tabular}{cccccc}
\hline Hospital & $\mathbf{2 0 0 3}$ & $\mathbf{2 0 0 4}$ & $\mathbf{2 0 0 5}$ & $\mathbf{2 0 0 6}$ & $\mathbf{2 0 0 7}$ \\
\hline For-Profit Hospitals (86) & 13.6 & 14.1 & 14.6 & 14.6 & 14.7 \\
Nonprofit Hospitals (184) & 58.0 & 56.5 & 58.2 & 59.9 & 59.3 \\
\hline
\end{tabular}

Note: The number of observations is given in parentheses.

\subsection{Hospital Quality}

Next, we consider the quality of hospitals in California. In this study, a measure of hospital inpatients' mortality rate is used to indicate quality. Inpatient mortality indicators form a set of measures that provide a perspective on the quality of hospital care using patient data routinely reported to the OSHPD. The indicators include medical conditions and procedures for which mortality rates vary significantly across institutions. Evidence suggests that high mortality may be associated with deficiencies in the quality of hospital care provided. These indicators (Inpatient Quality Indicators (Fishers Lane, Rockville, MD, USA), Version 3.2) were developed by the Agency for Healthcare Research and Quality (AHRQ), a federal agency, and are provided by the OSHPD for use by California consumers and healthcare purchasers and providers. Eight of the fifteen AHRQ Inpatient Quality Indicators are produced by the OSHPD for public release and are analyzed in this study. Five of them are related to in-hospital deaths after surgery, and three are related to in-hospital deaths after treatment for some medical conditions. Tables 4 and 5 display these measures of hospital quality in California for the sample period.

Table 4. Hospital Quality (In-hospital Deaths after Surgery-Risk-adjusted Mortality Rate).

\begin{tabular}{|c|c|c|c|c|c|c|c|c|c|c|}
\hline \multirow{2}{*}{$\begin{array}{l}\text { Hospital Size } \\
\text { (Number of } \\
\text { Licensed Beds) }\end{array}$} & \multicolumn{2}{|c|}{$\begin{array}{c}\text { Esophageal } \\
\text { Resection }\end{array}$} & \multicolumn{2}{|c|}{$\begin{array}{l}\text { Pancreatic } \\
\text { Resection }\end{array}$} & \multicolumn{2}{|c|}{ Craniotomy } & \multicolumn{2}{|c|}{$\begin{array}{c}\text { Carotid } \\
\text { Endarterectomy }\end{array}$} & \multicolumn{2}{|c|}{$\begin{array}{c}\text { Percutaneous } \\
\text { Transluminal } \\
\text { Coronary Angioplasty }\end{array}$} \\
\hline & FPH & NPH & FPH & NPH & FPH & NPH & FPH & NPH & FPH & NPH \\
\hline$<50$ & NA & NA & NA & NA & NA & NA & NA & $0(2)$ & NA & NA \\
\hline 50-100 & NA & NA & NA & NA & NA & NA & $0(4)$ & $0(3)$ & $1.75(2)$ & NA \\
\hline $100-150$ & NA & NA & NA & $0(2)$ & $2.42(4)$ & $4.86(3)$ & $0(4)$ & $0.36(15)$ & $1.10(3)$ & $0.97(4)$ \\
\hline $150-200$ & NA & NA & NA & $18.93(3)$ & $4.29(10)$ & $6.9(7)$ & $0.66(9)$ & $0.17(15)$ & $1.01(6)$ & $1.14(10)$ \\
\hline $200-250$ & NA & $0(1)$ & NA & $0(6)$ & $5.56(6)$ & $3.61(14)$ & $0.137(8)$ & $0.52(15)$ & $1.16(5)$ & $0.82(10)$ \\
\hline $250-300$ & NA & $0(1)$ & NA & $0(3)$ & $9.65(2)$ & $6.14(10)$ & $0.9(2)$ & $0.71(19)$ & $0(2)$ & $1.48(13)$ \\
\hline $300-350$ & NA & $44.9(1)$ & NA & $2.9(5)$ & $7.9(1)$ & $6.43(14)$ & $0(1)$ & $0.27(16)$ & $1.6(1)$ & $1.10(13)$ \\
\hline $350-400$ & NA & NA & NA & $4.4(4)$ & $6.3(2)$ & $6.02(10)$ & $0.5(2)$ & $0.35(13)$ & $1.05(2)$ & $1.4(7)$ \\
\hline $400-450$ & $4.4(1)$ & NA & $0(2)$ & $11.09(10)$ & $4.98(5)$ & $5.97(13)$ & $0.46(5)$ & $0.38(14)$ & $0.72(4)$ & $1.31(13)$ \\
\hline $450-500$ & NA & $0(1)$ & NA & $19.4(3)$ & $9.6(1)$ & $6.2(9)$ & 1(1) & $0.17(9)$ & $1.6(1)$ & $1.41(8)$ \\
\hline $500-550$ & NA & $0(1)$ & NA & $0(4)$ & NA & $6.33(6)$ & NA & $0(6)$ & NA & $1.22(5)$ \\
\hline $550-600$ & NA & $0(1)$ & NA & 8.3(1) & NA & $12.5(3)$ & NA & $0(3)$ & NA & $1.7(2)$ \\
\hline $600-650$ & NA & $4.1(2)$ & NA & $21.3(3)$ & NA & 7.1(3) & NA & $0(3)$ & NA & $1.86(3)$ \\
\hline 650-1000 & NA & $0(2)$ & NA & $5.7(2)$ & NA & $6.43(3)$ & NA & $0(3)$ & NA & $1.26(3)$ \\
\hline$>1000$ & NA & $34.3(1)$ & NA & $0(1)$ & NA & $7.8(1)$ & $0(1)$ & $0(1)$ & NA & $1.5(1)$ \\
\hline Total & $4.4(1)$ & 7.94(11) & $0(2)$ & $7.26(47)$ & $5.17(31)$ & $6.06(96)$ & $0.32(37)$ & $0.33(137)$ & $1.08(26)$ & $1.25(92)$ \\
\hline
\end{tabular}

Note: The number of observations is given in parentheses. 
Table 5. Hospital Quality (In-Hospital Deaths after Treatment for Specific Medical ConditionsRisk-adjusted Mortality Rate).

\begin{tabular}{ccccccc}
\hline \multirow{2}{*}{$\begin{array}{c}\text { Hospital Size (Number } \\
\text { of Licensed Beds) }\end{array}$} & \multicolumn{2}{c}{ Acute Stroke } & \multicolumn{2}{c}{$\begin{array}{c}\text { Gastrointestinal } \\
\text { Hemorrhage }\end{array}$} & Hip Fracture \\
\cline { 2 - 7 } & FPH & NPH & FPH & NPH & FPH & NPH \\
\hline$<50$ & $0(1)$ & $14.17(13)$ & $0(1)$ & $5.22(14)$ & NA & $4.8(10)$ \\
$50-100$ & $6.41(6)$ & $11.59(15)$ & $0.85(8)$ & $3.12(15)$ & $2.22(5)$ & $1.91(14)$ \\
$100-150$ & $8.1(21)$ & $11.96(24)$ & $2.08(21)$ & $2.75(24)$ & $1.39(21)$ & $1.84(24)$ \\
$150-200$ & $6.69(20)$ & $10.21(20)$ & $1.30(20)$ & $2.78(20)$ & $1.62(17)$ & $2.52(20)$ \\
$200-250$ & $10.28(10)$ & $9.21(19)$ & $2.36(11)$ & $1.75(18)$ & $4.82(10)$ & $2.07(18)$ \\
$250-300$ & $11.35(2)$ & $9.98(20)$ & $0.6(2)$ & $1.99(20)$ & $5.7(2)$ & $2.19(20)$ \\
$300-350$ & $10.9(1)$ & $9.92(17)$ & $2.1(1)$ & $1.72(17)$ & $2.3(1)$ & $1.65(17)$ \\
$350-400$ & $11.35(2)$ & $10.94(13)$ & $1.45(2)$ & $2.43(13)$ & $2.1(2)$ & $2.68(13)$ \\
$400-450$ & $7.84(5)$ & $11.36(15)$ & $2.42(5)$ & $1.84(15)$ & $1.76(5)$ & $2.05(14)$ \\
$450-500$ & $12.4(1)$ & $9.54(9)$ & $2(1)$ & $2.55(9)$ & $3.6(1)$ & $1.94(9)$ \\
$500-550$ & NA & $9.91(6)$ & NA & $1.56(6)$ & NA & $1.53(6)$ \\
$550-600$ & NA & $12.56(3)$ & NA & $2.4(3)$ & NA & $2.7(3)$ \\
$600-650$ & NA & $11(3)$ & NA & $1.33(3)$ & NA & $2.36(3)$ \\
$650-1000$ & NA & $10.53(3)$ & NA & $1.7(3)$ & NA & $2.8(3)$ \\
$>1000$ & $11.5(1)$ & $9.4(1)$ & $1(1)$ & $1.6(1)$ & $7.8(1)$ & $2.1(1)$ \\
Total & $5.17(31)$ & $10.85(96)$ & $8.06(70)$ & $2.49(181)$ & $1.69(73)$ & $2.25(175)$ \\
\hline
\end{tabular}

Note: The number of observations is given in parentheses.

Table 4 reports indicators related to in-hospital deaths after the following five types of surgery: esophageal resection, pancreatic resection, craniotomy, carotid endarterectomy, and percutaneous transluminal coronary angioplasty. Table 5 presents indicators related to in-hospital deaths after treatment for the following three medical conditions: acute stroke, gastrointestinal hemorrhage, and hip fracture.

These indicators are viewed as potentially useful starting points for examining hospital quality, but they are not regarded as absolute measures of quality. However, when this information and its limitations are carefully considered alongside other reliable healthcare provider information, this data may be helpful to patients and purchasers, such as insurance providers, when making decisions about healthcare. Healthcare providers may also benefit from using this information to improve quality.

Some hospitals tend to treat higher-risk patients, who have a greater chance of dying following a surgical procedure or treatment for a serious medical condition. To ensure that all California hospitals are assessed fairly, the OSHPD uses statistical risk adjustments to account for patient differences. Therefore, in this study, the risk-adjusted mortality rates for the aforementioned types of surgeries and treatments are used to measure hospital quality.

Among the risk-adjusted rates of in-hospital deaths after surgeries, only those of craniotomy, carotid endarterectomy, and percutaneous transluminal coronary angioplasty can be meaningfully compared between for-profit and nonprofit hospitals. However, neither type of hospital is found to provide much higher quality than the other in terms of these risk-adjusted mortality rates. Overall, for-profit hospitals have slightly lower mortality rates, but this result might be because they perform substantially fewer surgeries.

The risk-adjusted rates of in-hospital deaths after treatment for the aforementioned medical conditions are more comparable. For-profit hospitals provide better quality in the treatment of acute stroke and hip fracture, whereas nonprofit hospitals provide better quality in the treatment of gastrointestinal hemorrhage. Interestingly, for all treatment types, for-profit hospitals with under 200 licensed beds have lower mortality rates on average than nonprofit hospitals of the same size. However, nonprofit hospitals with 200-350 licensed beds exhibit better quality than similar-sized for-profit hospitals across all medical treatment types. 


\subsection{Proportion of Inpatients by Payer Type}

Table 6 displays the percentage of inpatients by payer type. Each number in the table is calculated in percentage as the number of discharges covered by each payer type over the total number of discharges from the selected hospitals each year. The payer types are Medicare, Medicaid (Medi-Cal), "other third parties," "indigent programs," and "other payers." For the Medicare, Medi-Cal, and "other third parties" payer types, both "traditional" and "managed" care are considered.

"Managed care" patients are patients enrolled in a managed care plan to receive health care from providers (specifically, from Health Maintenance Organizations) on a pre-negotiated or per diem basis. For example, the "Medicare managed care" category includes patients covered by a managed care plan funded by Medicare, whereas the "traditional Medicare" category includes patients covered under the Social Security Amendments of 1965. The "traditional Medi-Cal" category includes patients who qualify as needy under state laws. "Other third parties" includes patients enrolled in the Healthy Families program, Short-Doyle, and the Civilian Health and Medical Program of the Uniformed Services. The "other payers" (i.e., not the "other third parties") category includes self-paying patients.

Overall, the Medicare program covers over $40 \%$, other third parties cover about $30 \%$, and Medi-Cal covers over $20 \%$ of California patients. The percentage of for-profit hospitals' inpatients covered by Medicare increased by $9.3 \%$ from 2003 to 2007, whereas that of nonprofit hospitals did not change. However, the percentage of inpatients covered by Medi-Cal did not change for either hospital type. For both hospital types, the percentage of inpatients covered by other third parties slightly decreased during the five-year period. Therefore, the most notable change is the increase in the percentage of patients of for-profit hospitals covered by Medicare.

Table 6. Percentage of Inpatients by Payer Type.

\begin{tabular}{cccccccccccccc}
\hline \multirow{2}{*}{ Payer } & \multicolumn{2}{c}{2003} & \multicolumn{2}{c}{2004} & \multicolumn{2}{c}{ 2005 } & \multicolumn{2}{c}{ 2006 } & \multicolumn{2}{c}{ 2007 } & \multicolumn{3}{c}{ Total } \\
\cline { 2 - 16 } & FPH & NPH & FPH & NPH & FPH & NPH & FPH & NPH & FPH & NPH & FPH & NPH & Total \\
\hline Medicare & 44 & 42 & 45 & 42 & 46 & 42 & 47 & 42 & 45 & 42 & 42 & 44 & 42 \\
\hline Traditional & 38 & 32 & 40 & 31 & 40 & 33 & 40 & 31 & 39 & 32 & 34 & 38 & 32 \\
\hline Managed & 5 & 10 & 5 & 10 & 5 & 9 & 6 & 11 & 5 & 10 & 7 & 5 & 10 \\
\hline Medi-Cal & 25 & 17 & 25 & 18 & 25 & 18 & 25 & 18 & 26 & 17 & 22 & 25 & 17 \\
\hline Traditional & 20 & 13 & 20 & 13 & 19 & 13 & 19 & 13 & 20 & 13 & 17 & 20 & 13 \\
\hline Managed & 5 & 3 & 5 & 4 & 6 & 4 & 6 & 4 & 5 & 4 & 4 & 5 & 3 \\
\hline $\begin{array}{c}\text { Other Third } \\
\text { Parties }\end{array}$ & 24 & 34 & 23 & 34 & 22 & 33 & 22 & 33 & 23 & 34 & 29 & 24 & 34 \\
\hline Traditional & 5 & 18 & 5 & 7 & 5 & 9 & 6 & 5 & 5 & 8 & 8 & 5 & 18 \\
\hline Managed & 18 & 26 & 18 & 26 & 16 & 24 & 16 & 27 & 18 & 25 & 20 & 18 & 26 \\
\hline $\begin{array}{c}\text { Indigent } \\
\text { Program }\end{array}$ & 1 & 2 & 1 & 2 & 1 & 2 & 1 & 2 & 2 & 2 & 2 & 1 & 2 \\
\hline Other Payers & 3 & 2 & 2 & 3 & 2 & 3 & 3 & 2 & 3 & 3 & 3 & 3 & 2 \\
\hline Observations & 83 & 183 & 83 & 183 & 84 & 183 & 85 & 184 & 86 & 184 & 421 & 917 & 1648 \\
\hline
\end{tabular}

Note: FPH and NPH denote for-profit hospitals and nonprofit hospitals, respectively.

\subsection{Per Case Reimbursement}

We consider per case inpatient reimbursement to understand the financial schemes for hospital treatment reimbursements. To reflect the per unit charges of each hospital adjusted for illness, this study uses the case mix index (CMI). The CMI is the relative cost of the resources needed to treat the mix of patients in a licensed California hospital during a calendar year (Lee 2015). According to the OSHPD, the CMI can be used to adjust the average cost per patient for a given hospital relative to the adjusted average costs for other hospitals by dividing the average cost per patient by the hospital's calculated CMI (Meyer et al. 2007). Therefore, the adjusted average cost per patient reflects the charges 
reported for the types of cases treated in that year. For example, if a hospital has a CMI greater than 1.00, its adjusted cost per patient or per day will be lower than its unadjusted cost per patient, and, conversely, if a hospital has a CMI less than 1.00, its adjusted cost will be higher (Anyika 2015).

The per inpatient case amount received from each type of hospital payer is calculated by the following formula:

$$
P I R_{i j}=\frac{G I P_{i j}}{I P_{i j} * C M I_{i}} * \frac{N P R_{i j}}{G P R_{i j}}
$$

where $i=$ hospital and $j=$ Medicare, Medicaid (Medi-Cal), and other third parties. In Equation (2), PIR represents per inpatient reimbursement, GIP is gross inpatient revenue, IP is the number of inpatients, NPR is net patient revenue, and GPR is gross patient revenue. As following the rule of Internal Revenue Service, the first part of Equation (2) represents charges adjusted per inpatient case at the hospital's full, established rates for the provision of patient care services, before deductions from revenue are applied. The second part of Equation (2) represents the proportion of the full amount that is actually received from third-party payers. Since net inpatient revenue is unavailable, PIR is calculated using the proportion of the amount of total patient revenue. Table 7 shows the per case reimbursement by payer type in each type of hospital.

Table 7. Reimbursement by Payer (\$).

\begin{tabular}{|c|c|c|c|c|c|c|c|c|c|c|}
\hline \multirow{2}{*}{ Payer } & \multicolumn{2}{|c|}{2003} & \multicolumn{2}{|c|}{2004} & \multicolumn{2}{|c|}{2005} & \multicolumn{2}{|c|}{2006} & \multicolumn{2}{|c|}{2007} \\
\hline & FPH & NPH & FPH & NPH & FPH & NPH & FPH & NPH & FPH & NPH \\
\hline \multicolumn{11}{|c|}{ Medicare } \\
\hline Traditional & $\begin{array}{c}9258 \\
(79)\end{array}$ & $\begin{array}{l}8115 \\
(157)\end{array}$ & $\begin{array}{c}9401 \\
(80)\end{array}$ & $\begin{array}{l}8310 \\
(158)\end{array}$ & $\begin{array}{c}10,808 \\
(81)\end{array}$ & $\begin{array}{l}8684 \\
(156)\end{array}$ & $\begin{array}{c}13,047 \\
(83)\end{array}$ & $\begin{array}{c}10,095 \\
(154)\end{array}$ & $\begin{array}{c}10,515 \\
(81)\end{array}$ & $\begin{array}{l}9746 \\
(156)\end{array}$ \\
\hline Managed & $\begin{array}{c}11,043 \\
(63)\end{array}$ & $\begin{array}{l}9826 \\
(119)\end{array}$ & $\begin{array}{c}14,752 \\
(64)\end{array}$ & $\begin{array}{l}9858 \\
(122)\end{array}$ & $\begin{array}{c}12,371 \\
(62)\end{array}$ & $\begin{array}{c}10,877 \\
(123)\end{array}$ & $\begin{array}{c}12,872 \\
(64)\end{array}$ & $\begin{array}{c}12,417 \\
(123)\end{array}$ & $\begin{array}{c}11,433 \\
(66)\end{array}$ & $\begin{array}{c}11,410 \\
(127)\end{array}$ \\
\hline \multicolumn{11}{|c|}{ Medi-Cal } \\
\hline Traditional & $\begin{array}{l}7937 \\
(77)\end{array}$ & $\begin{array}{l}7146 \\
(156)\end{array}$ & $\begin{array}{c}8004 \\
(76)\end{array}$ & $\begin{array}{l}7476 \\
(158)\end{array}$ & $\begin{array}{c}7442 \\
(76)\end{array}$ & $\begin{array}{l}8550 \\
(156)\end{array}$ & $\begin{array}{c}12,028 \\
(79)\end{array}$ & $\begin{array}{c}14,035 \\
(153)\end{array}$ & $\begin{array}{c}10,828 \\
(79)\end{array}$ & $\begin{array}{l}9611 \\
(156)\end{array}$ \\
\hline Managed & $\begin{array}{c}8385 \\
(68)\end{array}$ & $\begin{array}{l}5524 \\
(112)\end{array}$ & $\begin{array}{c}8975 \\
(70)\end{array}$ & $\begin{array}{l}5945 \\
(113)\end{array}$ & $\begin{array}{c}8074 \\
(69)\end{array}$ & $\begin{array}{l}5626 \\
(120)\end{array}$ & $\begin{array}{c}8799 \\
(69)\end{array}$ & $\begin{array}{l}6642 \\
(115)\end{array}$ & $\begin{array}{l}8527 \\
(71)\end{array}$ & $\begin{array}{l}7562 \\
(118)\end{array}$ \\
\hline \multicolumn{11}{|c|}{ Other Third Parties } \\
\hline Traditional & $\begin{array}{c}15,159 \\
(74)\end{array}$ & $\begin{array}{l}13,087 \\
(155)\end{array}$ & $\begin{array}{c}19,854 \\
(78)\end{array}$ & $\begin{array}{c}14,241 \\
(156)\end{array}$ & $\begin{array}{c}21,394 \\
(78)\end{array}$ & $\begin{array}{c}14,402 \\
(155)\end{array}$ & $\begin{array}{c}23,945 \\
(80)\end{array}$ & $\begin{array}{c}17,657 \\
(152)\end{array}$ & $\begin{array}{c}19,220 \\
(78)\end{array}$ & $\begin{array}{c}17,551 \\
(153)\end{array}$ \\
\hline Managed & $\begin{array}{c}9190 \\
(70)\end{array}$ & $\begin{array}{l}8885 \\
(128)\end{array}$ & $\begin{array}{c}9773 \\
(69)\end{array}$ & $\begin{array}{c}11,224 \\
(129)\end{array}$ & $\begin{array}{c}11,626 \\
(71)\end{array}$ & $\begin{array}{c}11,159 \\
(131)\end{array}$ & $\begin{array}{c}13,411 \\
(72)\end{array}$ & $\begin{array}{c}14,058 \\
(133)\end{array}$ & $\begin{array}{c}12,665 \\
(73)\end{array}$ & $\begin{array}{c}13,169 \\
(135)\end{array}$ \\
\hline
\end{tabular}

Note: FPH and NPH denote for-profit hospitals and nonprofit hospitals, respectively.

In general, hospital reimbursement increases over the study period, with a drop in 2007. For-profit hospitals are reimbursed more than nonprofit hospitals are per treatment case. Hospitals are reimbursed more when treating patients covered by other third parties than when treating those on Medicare or Medicaid. For-profit hospitals are reimbursed slightly more than nonprofit hospitals, whereas the reimbursement amounts for Medicare managed care are almost the same for the two hospital types.

\subsection{Other Independent Variables of For-Profit Hospitals}

As described previously, three categories of independent variables are used in this study: the proportion of inpatient utilization by payer type, the number of licensed beds by type of care, and direct expenses by cost center group. The payer types provided by each hospital are specified as the two managed care programs (Medicare and Medi-Cal), other third parties, indigent programs, and self-pay. This study uses the managed care programs, Medicare and Medi-Cal, since they accurately 
reflect the current prospective payment system. A second independent variable is licensed bed utilization according the type of care provided by each hospital, specified as acute, psychiatric, chemical dependency, rehabilitation, or long-term.

The last independent variable category is direct expenses, which are categorized as ambulatory, ancillary, purchased, and general services and as hospital and malpractice insurance. Table 8 provides information on the data used in the empirical analysis and the means and standard deviations of the variables used in the estimation. Of the 430 total data sets of for-profit hospitals over the five-year period, 244 had no missing values and, thus, were used in the empirical analysis.

Table 8. Variables, Means, and Standard Deviations.

\begin{tabular}{|c|c|c|}
\hline Variable $(\mathrm{N}=244)$ & Mean & Standard Deviation \\
\hline Market Share & 0.0018 & 0.0014 \\
\hline \multicolumn{3}{|c|}{ Proportion of Inpatients by Payer Type } \\
\hline \multicolumn{3}{|l|}{ Medicare } \\
\hline Managed Care Medicare & 0.0575 & 0.0737 \\
\hline Traditional Care Medicare & 0.3968 & 0.2055 \\
\hline \multicolumn{3}{|l|}{ Medicaid (Medi-Cal) } \\
\hline Managed Care Medi-Cal & 0.0599 & 0.0652 \\
\hline Traditional Care Medi-Cal & 0.2001 & 0.1683 \\
\hline \multicolumn{3}{|l|}{ Other Third Party } \\
\hline Managed Care Other Third Party & 0.1800 & 0.1705 \\
\hline Traditional Care Other Third Party & 0.0578 & 0.0976 \\
\hline Self-Pay & 0.0294 & 0.0312 \\
\hline Indigent Program & 0.0179 & 0.0235 \\
\hline \multicolumn{3}{|l|}{ Licensed Bed Utilizations by Type of Care } \\
\hline Acute Care & 140.73 & 98.115 \\
\hline Psychiatric Care & 12.263 & 22.628 \\
\hline Chemical Dependency Care & 0.6233 & 3.5672 \\
\hline Patient Rehabilitation & 4.3698 & 9.9876 \\
\hline Patient Long-term Care & 10.972 & 19.066 \\
\hline \multicolumn{3}{|l|}{ Direct Expenses } \\
\hline Ambulatory Services & $4,097,911$ & $4,470,380$ \\
\hline Ancillary Services & $26,900,000$ & $25,900,000$ \\
\hline General Services & $9,958,628$ & $8,474,563$ \\
\hline Purchased Services & $11,500,000$ & $11,400,000$ \\
\hline Insurance-Hospital \& Professional Malpractice & $1,243,294$ & $1,164,995$ \\
\hline
\end{tabular}

\section{Results}

To test for random effects, the Breusch and Pagan (1980) Lagrange multiplier test was conducted. The obtained Lagrange multiplier test statistic was 262.03, which far exceeds 3.84, the 95\% critical value for a chi-squared distribution with one degree of freedom. This result implies that a classical model with a single constant term is inappropriate for the data. Instead, a random effects model should be used. Because a fixed effects model might produce the same results, the Hausman test was conducted as well, resulting in a test statistic of 1.02. The critical value for the chi-squared distribution with thirteen degrees of freedom is 22.36, which is far larger than the test statistic value. As a result, the hypothesis that individual hospital effects are uncorrelated with other variables in the model cannot be rejected. Both test results indicate that a random effects model is the better choice. Table 9 presents the results of the random effects model analysis of the relative market share equation for for-profit hospitals.

Two-step estimations are utilized to fully investigate the effect of prospective reimbursements on market share. The first step is estimating the prospective reimbursement effects of quality improvements and cost-saving investments, and the second step is estimating the effect of these changes in investments on the relative market share of for-profit hospitals. Unfortunately, data for direct quality improvements and cost saving investments are unavailable, so two-step estimation cannot be conducted. Instead, this study investigates the overall, indirect, prospective reimbursement 
effects on the relative market share. The relative market share equation of the for-profit hospitals is estimated using the generalized least squares method, and most of the explanatory variables have significance levels of at least $10 \%$.

The most important result in the context of this analysis is that the proportion of patients paying with Medicare managed care increases the market share of for-profit hospitals (significant at the $1 \%$ level). Because Medicare managed care reimburses the health care provider prospectively, we can infer that a larger portion of prospective reimbursements is received by for-profit hospitals, thus increasing the market share of for-profit hospitals. A larger proportion of patients with Medi-Cal managed care and other third party coverage significantly increases the market share of for-profit hospitals.

Having more beds for acute, psychiatric, and rehabilitation care also increases the relative market share of for-profit hospitals; this result is because most patients in a general hospital (91\%) receive these three types of care.

Of the direct expenses analyzed, ancillary services, general services, and hospital and professional malpractice insurance all increase the market share of for-profit hospitals with a significance of at least 10\%. Ancillary services include specific diagnostic or therapeutic services for patients. Convenient ancillary services, therefore, can play a significant role in a patient's choice of hospital. Because ancillary services are special services that involve case-specific charges in addition to routine charges, they produce more revenue than routine diagnostic services do. Direct expenses related to general services include non-revenue-producing costs, such as dietary and hospital maintenance, which implies that for-profit hospitals invest more in amenities in order to obtain a larger market share.

The result for hospital and professional malpractice insurance can be explained from a cost and treatment perspective. As for-profit hospitals purchase more malpractice insurance, their malpractice liability is reduced, and operating costs decrease. Decreased costs can potentially increase the quality of hospital care and, thus, increase market share. Alternatively, from a treatment perspective, malpractice insurance can be a backup for loss-making services that induces the active treatment of high-risk patients, which attracts more patients.

Table 9. Relative Market Share Equation of For-profit Hospitals.

\begin{tabular}{lcc}
\multicolumn{1}{c}{ Variable } & $\begin{array}{c}\text { Random Effects } \\
\text { Coefficient }\end{array}$ & $\begin{array}{c}\text { Standard } \\
\text { Error }\end{array}$ \\
\hline Proportion of Inpatients by Payer Type & & \\
Medicare Managed Care & $0.0012^{* * *}$ & 0.0005 \\
Medicaid (Medi-Cal) Managed Care & $0.0011^{* * *}$ & 0.0004 \\
Other Third Party & $0.0012^{* * *}$ & 0.0002 \\
Self-Pay & -0.0002 & 0.0006 \\
Indigent Program & 0.0006 & 0.0009 \\
Licensed Bed Utilizations by Type of Care & & 0.0236 \\
Acute Care (in \$100,000s) & $0.0536^{* *}$ & 0.0198 \\
Psychiatric Care (in \$10,000s) & $0.0469^{* *}$ & 0.0138 \\
Chemical Dependency Care (in \$1,000s) & -0.0201 & 0.0464 \\
Patient Rehabilitation (in \$1,000s) & $0.0102^{* *}$ & 0.0232 \\
Patient Long-term Care (in \$10,000s) & 0.0359 & 0.0089 \\
Direct Expenses & & 0.0289 \\
Ambulatory Services (in \$1,000,000,000s) & -0.0134 & 0.0731 \\
Ancillary Services (in $\$ 1,000,000,000 s)$ & $0.0127^{* * *}$ & 0.0395 \\
General Services (in \$10,000,000,000s) & $0.0665^{*}$ & 0.0021 \\
Purchased Services (in \$10,000,000,000s) & 0.0138 & 0.0001 \\
Insurance-Hospital \& Professional Malpractice (in \$100,000,000s) & $0.0121^{* * *}$ & $0.0006^{* * *}$ \\
Constant & 0.7078 & \\
Adjusted-R ${ }^{2}$ & & \\
\hline
\end{tabular}

Notes: ${ }^{* * *},{ }^{* *}$, and ${ }^{*}$ indicate statistical significance at the $1 \%, 5 \%$, and $10 \%$ levels, respectively. 


\section{Conclusions}

This study investigates the determinants of market share of for-profit hospitals. In particular, it focuses on the effect of a prospective payment system on for-profit hospital growth. The findings show that the proportion of patient care paid by Medicare managed care is positively associated with the market share of for-profit hospitals. A larger portion of prospective reimbursements is received by for-profit hospitals, and since Medicare managed care reimburses health care providers prospectively, a higher proportion of Medicare managed care increases the market share of for-profit hospitals. We also find that the proportion of inpatients with Medi-Cal and other third-party managed care is positively associated with the market share of for-profit hospitals.

Acknowledgments: The paper is reorganized based on the empirical part of Seungchul Lee's Ph.D. dissertation at Washington State University. This research was supported by the Chung-Ang University Research Scholarship Grants in 2016.

Author Contributions: The authors contributed equally to this work.

Conflicts of Interest: The authors declare no conflict of interest.

\section{References}

Anyika, Chinwe. 2015. Modeling and Analysis of a Clinical Documentation Improvement System: Calculating Patient Outcomes. Ph.D. dissertation, Rutgers University-School of Health Related Professions, Chung, Newark, NJ, USA.

Araújo, Cláudia, Carlos P. Barros, and Peter Wanke. 2014. Efficiency determinants and capacity issues in Brazilian for-profit hospitals. Health Care Management Science 17: 126-38. [CrossRef] [PubMed]

Bays, Carson W. 1983. Patterns of hospital growth: The case of profit hospitals. Medical Care 21: 850-57. [CrossRef] [PubMed]

Brekke, Kurt R., Luigi Siciliani, and Odd Rune Straume. 2011. Hospital competition and quality with regulated prices. The Scandinavian Journal of Economics 113: 444-69. [CrossRef]

Breusch, Trevor Stanley, and Rodney Pagan Pagan. 1980. The Lagrange multiplier test and its applications to model specification in econometrics. The Review of Economic Studies 47: 239-53. [CrossRef]

Brown, Edmund G., Jr., Douglas Sale, and Stephanie Clendenin. 2011. Office of statewide health planning and development California workforce investment board health workforce development council career pathway sub-committee final report 2011. Available online: https://pdfs.semanticscholar.org/bfca/ 1495f9f433d4fc331dcc51fa82a09783bbae.pdf (accessed on 15 May 2012).

Chang, Tom, and Mireille Jacobson. 2011. What do Nonprofit Hospitals Maximize? Evidence from California's Seismic Retrofit Mandate. NBER Working Paper Series. Available online: http:/ / users.nber.org/ jacobson/ ChangJacobson12.5.10.pdf (accessed on 13 March 2012).

Friesner, Daniel L., and Robert Rosenman. 2002. Cost shifting revisited: The case of service intensity. Health Care Management Science 5: 15-24. [CrossRef] [PubMed]

Gawande, Atul. 2009. The cost conundrum. The New Yorker, June 1, pp. 36-44.

Gaynor, Martin, and Robert Town. 2012. The impact of hospital consolidation-update. The Synthesis Project. Robert Wood Johnson Foundation. [CrossRef]

Herr, Annika. 2011. Quality and welfare in a mixed duopoly with regulated prices: The case of a public and a private hospital. German Economic Review 12: 422-37. [CrossRef]

Lakdawalla, Darius, and Tomas Philipson. 2006. The nonprofit sector and industry performance. Journal of Public Economics 90: 1681-98. [CrossRef]

Langland-Orban, Barbara, John T. Large, Alan M. Sear, Hanze Zhang, and Nanhua Zhang. 2015. Operating profitability of for-profit and not-for-profit Florida community hospitals during Medicare policy changes, 2000 to 2010. INQUIRY: The Journal of Health Care Organization, Provision, and Financing 52. [CrossRef] [PubMed]

Lee, Seungchul. 2010. Reimbursement and Investment: Why Market Share of For-Profit Hospitals Increased after Prospective Payment. Ph.D. dissertation, Washington State University of WA, Pullman, WA, USA. 
Lee, Jinhyung. 2015. Network Effects of Health Information Technology: Evidence from California Hospitals. Korean Economic Review 31: 359-81.

Lee, Seungchul, and Robert E. Rosenman. 2013. Reimbursement and investment: Prospective payment and for-profit hospitals' market share. Journal of Industry, Competition and Trade 13: 503-18. [CrossRef]

Meyer, Elisabeth, Juergen Buttler, Christian Schneider, Egid Strehl, Barbara Schroeren-Boersch, Petra Gastmeier, Henning Ruden, Josef Zentner, Franz D. Daschner, and Frank Schwab. 2007. Modified guidelines impact on antibiotic use and costs: Duration of treatment for pneumonia in a neurosurgical ICU is reduced. Journal of antimicrobial chemotherapy 59: 1148-54. [CrossRef] [PubMed]

Sloan, Frank A. 2000. Not-for-profit ownership and hospital behavior. Handbook of Health Economics 1: 1141-74.

Solutions, Treo. 2004. Costs, commitment and locality: A comparison of for-profit and not-for-profit health plans. INQUIRY: The Journal of Health Care Organization, Provision, and Financing 41: 116-29. [CrossRef] [PubMed]

Spetz, Joanne, Jean Ann Seago, and Shannon Mitchell. 1999. Changes in Hospital Ownership in California. San Francisco: Public Policy Institute of California.

Teno, Joan M., Susan L. Mitchell, Pedro L. Gozalo, David Dosa, Amy Hsu, Orna Intrator, and Vincent Mor. 2010. Hospital characteristics associated with feeding tube placement in nursing home residents with advanced cognitive impairment. JAMA 303: 544-50. [CrossRef] [PubMed]

Woolhandler, Steffie, and David U. Himmelstein. 2004. The high costs of for-profit care. Canadian Medical Association Journal 170: 1814-15. [CrossRef] [PubMed]

(C) 2017 by the authors. Licensee MDPI, Basel, Switzerland. This article is an open access article distributed under the terms and conditions of the Creative Commons Attribution (CC BY) license (http:/ / creativecommons.org/licenses/by/4.0/). 